\title{
Post Crisis: The Future of Cryptocurrency Against the U.S. Dollar
}

\author{
Kelly Oniha* \\ A.R. Sanchez, Jr. School of Business, Texas A\&M International University, \\ 5201 University Blvd, Laredo, TX 78041 \\ * E-mail of the corresponding author: kellyoniha@dusty.tamiu.edu
}

\begin{abstract}
There have been many economists who predicted prior to the pandemic, a rising surge in the cryptocurrencies in the future if financial activities especially when new entrants start to enter the market. Due to the volatility in cryptocurrencies since its creation in 2009 , It is paramount to keep track of this somewhat recent effect on the financial market. Bitcoin, one of the cryptocurrencies was said to be created to mitigate against the effect of the financial crisis of 2008. To some extent, many believed it to have done its job. This study focuses on how the cryptocurrencies have fared against the dollar and what the future holds for it during this coronavirus pandemic. Ofcourse, the crisis might have little effect on mortgage credits, business or broadly, the financial system but due to the rising use and price of the cryptocurrency, it is obvious this might shake or trigger the financial economy. A survey research design was adopted consisting of 50 bank staff in San Angelo, Texas. A mean score rating method was used to analyze the data and the responses, while in addressing the hypothesis, the chi-square was used to test the effect it has had on the dollar. The results showed that the effect of the cryptocurrencies against the dollar might be significantly low in the future. It implies that despite the expected increase in the cryptocurrencies during "lockdown", cryptocurrencies would have little to no effect on the dollar in future since it would still carry a relatively small percentage in future due to its volatility and risk.
\end{abstract}

Keywords: Cryptocurrency, digital currency, virtual currency, fiat dollar, bitcoins, halving

DOI: $10.7176 /$ RJFA/11-14-01

Publication date:July $31^{\text {st }} 2020$

\section{Introduction}

There have been improved procedures in money payment in the financial market presently. Nowadays, transactions can be conducted via a digital card, internet and phone (Dwyer, 2015). This has brought about several alternative payment methods like Paypal, BitPay, Wallet, Apple pay, M-Pesa, Moven, FAST, Venmo, CashApp, and others. With the increasing use of cryptocurrencies, more importantly bitcoin, which peaked in April 2013, where it had almost 2 million in value, coupled with the ever increasing US population, it is easy to picture the growth of digital currency across the globe and how this might affect the financial market, especially during a post crisis. Digital currencies offer speedy, flexible and innovative medium of payment which makes it very much more favorable than making payment traditionally. One digital currency stands heads and shoulders, above the rest, and that is Bitcoin, the most advanced cryptocurrency of them all.

Cryptocurrency, often regarded as a digital asset uses cryptography derived from blockchain innovation that acts as a medium of exchange for transactions. It generates encryption which helps control units of currency and verifies transactions independently from the bank. Since its inception in 2008, it has gained widespread acceptance and use in the financial market.Cryptocurrencies using cryptography include swiss coin,billion coin, mining, one coin, bitcoin, among others. Bitcoin for one, needs just for one to subscribe to it. It does not require bank aid. These bitcoins can be converted to cash and are already in use globally. Mining, a cryptocurrency puts coins up for sale digitally. It is important to note that trading digital currencies only happens peer to peer. By 2013, Bitcoin created was already 14 million and this increases by 25 every 8 minutes. Bitcoin, due to its popularity, has become the currency of the internet if the internet were a "country". This is the only point in time in the financial market where the end user actually is in control of the digital asset without relying on an account in any financial institution. It tackles several cons experienced with the traditional money. For example, it is very helpful in moving incentives to the user in circumstances where the monetary framework is deficient. Payments are fast and it is usually settled within minutes. Its main goal was not only to help in the financial crisis but to provide an alternative to the existing payments system. However, it also shares some similarities, Bitcoin does not have any intrinsic value like cash (Jacob Kosoff, 2019) and like cash, it can also be tradable. Cryptocurrency now has a massive market for it worth billions of U.S. dollars. There are several risks to trading cryptocurrencies. Bitcoin fell by more than $50 \%$ from December 2017 to February 2018. This will most likely scare off the risk averse investors. It is very highly liquid which means a small change in the financial market can be detrimental to its trade.

To use bitcoin, a client must have an open key and private key known widely as square chain. If a client misplaces a private key, the cryptocurrency becomes useless because the value of the cryptocurrency becomes lost. In September 2018, cryptocurrencies crashed by $80 \%$ after its peak. Two months later, bitcoin fell by over 
$80 \%$ too from its peak according(wikipedia,2018). This event allowed the market capitalization and the price of bitcoin to decrease below \$100billion and to \$5,500 respectively. Larry Fink in 2018, predicted less growth in bitcoins if the slip in the economy is as a result of trade imbalances or trade problems. Economists, experts and analysts in 2018 predicted a crash would most likely devalue the dollar purchasing power. This prediction turns out to be false during this coronavirus pandemic. Dollar value according to the Bureau of Labor Statistics, are $49.71 \%$ higher than its average since 2000. Despite the crisis, it has increased $2.04 \%$ per year (Bureau of Statistics, 2020). This is not to downgrade the influence cryptocurrencies have had in the economy, after all, people see bitcoin as the solution to the financial crisis. Bitcoin has helped transform the global economy. Investors in bitcoins are increasing everyday and it currently trades at about $\$ 9,156$ approximately. Due to its complexity and the simplicity the dollar offers, it is hard to picture bitcoins ever replacing dollar cash. Mike Orcut (2020) argued that coronavirus has in fact had a negative effect on bitcoins as investors are beginning to realize it is not a "safe haven" as intended. Bitcoins might even just be another financial asset and not intended to be any other things as originally supposed to be. Even if the Federal Government succeeds in creating its own cryptocurrency, Fedcoin, it is still going to be slow in its use and not a very good store of value, thus having little effect or no effect on the dollar. Table 1.

Data from Refinitiv showed an initial slump in the value of bitcoin on March 18, 2020 during the start of the lockdown period, but it peaked up to its original price after three months despite the evidence of the coronavirus. More importantly, it has become fairly stable as shown below.

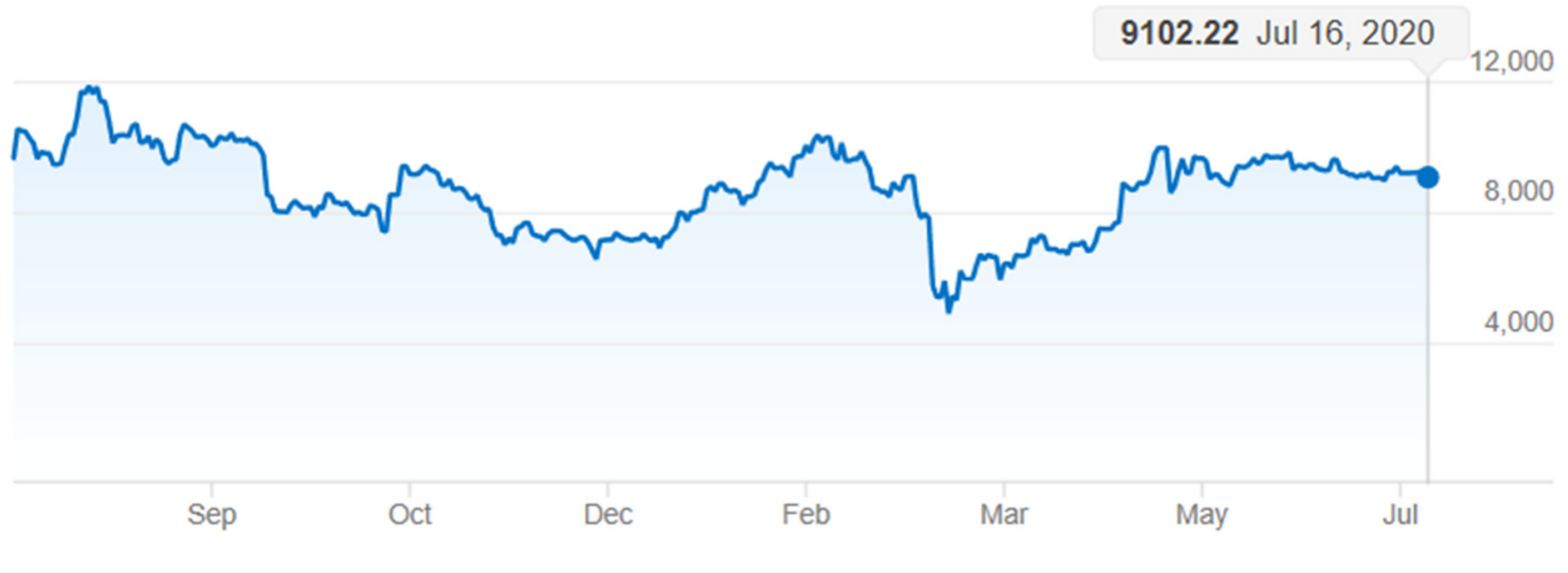

Bitcoins has many shortcomings but in today's complex world, it should be very easy to send money internationally, for example, something that makes bitcoin favorable but this is not backed by gold and a $\$ 200$ today can be $\$ 50$ tomorrow or $\$ 300$ tomorrow. It is highly volatile and scares a lot of people. There are still people who trade in bitcoins but these are risk takers.

\section{Fiat U.S. dollar currency}

There are broadly 3 factors that affect the dollar; they are supply and demand, technical and market psychology. Despite the growing use of bitcoins and the ease of the transactions of bitcoins, it is hard to see a picture of a huge slump or rise in comparison to the dollar value in future years due to the pandemic. Unemployment rate also has a huge say in this. According to Rakesh, 2020, the unemployment rate in the US has risen higher in 3 months than it did in two years. With limited resources available people would most likely not want to trade in bitcoins, instead they would be sourcing for available cash. The US dollar is currently in bull mode and is likely to remain the same. The federal Government is a huge financial player in the economy and will want to use its federal reserves to bail out companies thereby forcing the use of the dollar currency. The US dollar is one of the safest currencies in the world and even cryptocurrencies would have a hard time replacing it in the future, if not impossible. The US is the largest importer and most commodities traded are in dollars. Moreover, even countries hold dollars as a reserve, and this ensures that it remains stable which makes the dollar crisis unlikely. The bitcoin usage does not have enough power to destabilize the US dollar. Few things that could destabilize it include increased trade deficits, federal debts and weakness of the middle class.

\subsection{Digital Currencies}

Digital currencies transcends past geographical boundaries despite its complicated nature. It is widely expected to become easier as years go by. This would make it very much easier to transact businesses in the near future. One of its best features still is the lower transaction fees incurred in transacting with cryptocurrencies. Privacy has also made it all the more desirable. Take for example, Altcoin, which helps ensure privacy of its users as individuals 
do not have to share personal information that makes it easy for others to identify. Cryptocurrency is not a legal tender, it is merely a financial asset, more like a digital asset without control from any regulation. Their decentralization has made governments in other countries banned its usage. Cryptocurrencies have a cap limit of 21 million which limits its supply. In contrast, fiat dollar does not have a cap limit. The implication of this is that the fiat dollar will continue to be in use as long as it is printed by the federal reserve making the effect of digital currency of it somewhat inexistent. There has been much support for cryptocurrencies over fiat. Robert Kiyoshi, an author, felt due to the number of faux money, he has decided to trade in bitcoin (Alpha, 2019). There is no doubt that the crypto market will continue to evolve but would that necessarily mean the significant decline of the fiat US dollar? Many economists believe this to have that much significance. A lot of its use is based on preference of the user. It is why this study measures the behavior of a sample to this phenomenon. There are also others globally who do not back its use. Rogoff, Indian prime minister denounced its use, while Beijing wants to mitigate the use of bitcoin and libra adoption in China.

\subsection{Fiat U.S. dollar vs Digital Currencies}

Both perform the same function, which acts as a medium of exchange. The fiat has been around for centuries and although took a while to stabilize, it has become a norm. Cryptocurrency is still relatively new and the market for it is ever evolving. Even though it is complex, its use has gradually and slowly been increasing and users are beginning to learn to interact with it. Digital currency is the revolution the world needs but it will not eradicate the use of the fiat dollar as many people think. By eradicating the fiat money, the economy is more of less eradicating banks and regulatory financial institutions. The government is increasingly unlikely to let go of his control in the financial economy except it creates its own national cryptocurrency. If the federal Government chooses not to create its cryptocurrency, it is likely to mean, fiat dollars would continue to be stable in future. Even if financial institutions such as commercial banks, mortgage banks, merchant banks, etc are eradicated due to the emergence of cryptocurrencies, what would happen to loans, mortgages, payments of debts, and other factors that necessitates the use of fiat dollar currency? In addition, since it is not controlled, it has paved the way for it to be subject to criminal activities. There are no laws or regulations to prevent this which makes it very attractive to fraudsters. Alethea (2019), believes the idea of using cryptocurrencies is an interesting and exciting idea that can have a massive effect in the financial market, there are still a lot of issues presently evident that make its use in future a suspect.

Research Hypothesis

Ho The Effect of cryptocurrency on the value of the Fiat dollar is low

Hi The Effect of cryptocurrency on the value of the Fiat dollar is high

\section{Method and Data Analysis \\ 3.1 Research Design}

This study employed the use of descriptive survey research design. The choice of this research design was considered appropriate because of its advantages of identifying attributes of a large population from a group of individuals. The design was suitable for the study as the study was exploratory in nature and the use of digital currency against fiat dollar is by preference to the respondents.

\subsection{Population and Method}

This study aimed at collecting data from bankers, who are either Bitcoin users or individuals who have heard of Bitcoin in the past as an alternative payment method. It is believed that this would provide adequate information for the study and therefore give reliable results and findings. The study made use of primary sources of data. Concerning the primary source, a questionnaire was used to gather the data. The questionnaire was divided into two sections; section A is for the demographic information of the respondents, while section B was the main questions to address the research questions. The questionnaire is a four-point rating scale (Likert scale), starting from strongly agreed (SA), agreed (A), disagreed (d), and strongly disagreed (SD). The questionnaire was designed in such a way that every question in the questionnaire was related to the research questions and hypothesis of the study. Also the result was used to answer the research questions and test the relevant hypothesis. A mean score rating method was used to analyse the data based on the 2.5 acceptance region format to answer the research questions of the study, while to address the research hypothesis, the chi-square was used.

\subsection{Validity and Reliability}

The instrument was face validated by three experts in the field of measurement and evaluation and research. And a test- retest was conducted after a pilot survey using the same instruments in San Angelo, Texas, where a Crombach alpha statistics of 0.72 was obtained, showing that the instrument is reliable for the study. 
Table 2: Distribution of the Respondents based on their Gender

\begin{tabular}{|ll|l|l|l|l|}
\hline & Frequency & Percent & Valid Percent & Cumulative Percent \\
\hline Valid & Male & 15 & 30.0 & 30.0 & 30.0 \\
& Female & 35 & 70.0 & 70.0 & 100.0 \\
& Total & 50 & 100.0 & 100.0 & \\
\hline
\end{tabular}

Based on the result on table 4.1 above, it can be observed that about 30 percent of the respondents for this study are male, while a majority of 70 percent is female.

Table 3: Distribution of the Respondents based on their Marital Status

\begin{tabular}{|ll|l|l|l|l|}
\hline & Frequency & Percent & Valid Percent & $\begin{array}{l}\text { Cumulative } \\
\text { Percent }\end{array}$ \\
\hline Valid & Married & 23 & 46.0 & 46.0 & 46.0 \\
& Single & 6 & 12.0 & 12.0 & 58.0 \\
Widow & 19 & 38.0 & 38.0 & 96.0 \\
Separated & 2 & 4.0 & 4.0 & 100.0 \\
Total & 50 & 100.0 & 100.0 & \\
\hline
\end{tabular}

Based on the distribution of the respondents on their marital status, it is observed that about 23 of the respondents making up about 46 percent of the total respondents are married; while 38 percent of the respondents are widowed.

Table 4: Distribution of the Respondents based on their Age

\begin{tabular}{|ll|l|l|l|l|}
\hline & Frequency & Percent & Valid Percent & Cumulative Percent \\
\hline Valid & Below 20 years & 5 & 10.0 & 10.0 & 10.0 \\
21-30 years & 13 & 26.0 & 26.0 & 36.0 \\
31-40 years & 13 & 26.0 & 26.0 & 62.0 \\
41 years and above & 19 & 38.0 & 38.0 & 100.0 \\
Total & 50 & 100.0 & 100.0 & \\
\hline
\end{tabular}

From the responses on the age distribution of the respondents presented on table 4.3 above, it can be deduced that about 38 percent of the respondents are above 41 years of age, while 52 percent are in between the ages of 21 and 40.

Table 5: Distribution of the Respondents based on their highest Educational Qualification

\begin{tabular}{|c|c|c|c|c|c|}
\hline & & Frequency & Percent & Valid Percent & Cumulative Percent \\
\hline \multirow[t]{5}{*}{ Valid } & Masters Degree & 19 & 38.0 & 38.0 & 38.0 \\
\hline & B.Sc/B.ED & 19 & 38.0 & 38.0 & 76.0 \\
\hline & Ph.D & 9 & 18.0 & 18.0 & 94.0 \\
\hline & Other & 3 & 6.0 & 6.0 & 100.0 \\
\hline & Total & 50 & 100.0 & 100.0 & \\
\hline
\end{tabular}

Based on the distribution of the respondents based on their highest educational qualification, it can be 
observed that majority of the respondents have higher degrees of masters, this group comprises about 38 percent. Also the next 38 percent of the respondents are bachelor's degree holders while about 18 percent of the respondents are Ph.D holders.

\section{Answer to the Research Questions}

Research Question One: What is crypto currency?

Table 6: Responses of the respondents on what is crypto currency

\begin{tabular}{|l|l|l|l|l|l|}
\hline $\mathrm{S} / \mathrm{N}$ & Statement & $\mathrm{N}$ & Mean & Std. Deviation & Decision \\
\hline 1 & it is a digital money & 50 & 2.6000 & 1.03016 & Accepted \\
\hline 2 & can be used in making payment & 50 & 3.4000 & .63888 & Accepted \\
\hline 3 & example is Bitcoin & 50 & 2.9000 & .63888 & Accepted \\
\hline 4 & $\begin{array}{l}\text { can be transferred from one person } \\
\text { to the other }\end{array}$ & 50 & 2.5000 & .63888 & Accepted \\
\hline 5 & It is recognized in USA & 50 & 2.8000 & .75593 & Accepted \\
\hline & Valid N (listwise) & 50 & & & \\
\hline
\end{tabular}

Research Question Two: What are the effects of crypto currency on the value of the U.S. dollar?

Table 7: Responses of the respondents on the effects of crypto currency on the value of the U.S. dollar

\begin{tabular}{|l|l|l|l|l|l|}
\hline $\mathrm{S} / \mathrm{N}$ & Statement & $\mathrm{N}$ & Mean & Std. Deviation & Decision \\
\hline 1 & it reduces pressure on the dollars & 50 & 2.6000 & 1.03016 & Accepted \\
\hline 2 & it reduces the value of the dollars & 50 & 3.4000 & .63888 & Accepted \\
\hline 3 & It makes dollars worthless & 50 & 1.9000 & .23888 & Denied \\
\hline 4 & reduces the cost of printing the dollars & 50 & 1.5000 & .13888 & Denied \\
\hline 5 & reduces the cost of governance & 50 & 1.8000 & .15593 & Denied \\
\hline 6 & $\begin{array}{l}\text { The effect of the crypto currency on } \\
\text { value of the USA dollar in future is low }\end{array}$ & 50 & 2.7344 & .32454 & Accepted \\
\hline & Valid N (listwise) & 50 & & & \\
\hline
\end{tabular}

\section{Research Hypothesis:}

Ho1: the effect of the crypto currency on the value of the U.S. dollar is significantly low

Decision rule: Reject the null hypothesis if the Asymp level of significance is less than 0.05. Otherwise, do not reject the null hypothesis.

Table 8: Test of hypothesis table two

\section{Test Statistics}

\begin{tabular}{|l|c|}
\hline & the effect of the crypto currency on the value of the U.S. dollar is significantly low \\
\hline Chi-Square & $14.831^{\mathrm{a}}$ \\
df & 3 \\
Asymp. Sig. & .071 \\
\hline
\end{tabular}

a. 0 cells $(0.0 \%)$ have expected frequencies less than 5 . The minimum expected cell frequency is 25.0. 
Table 9 The table below derived from Crypto rating shows the predictions of some Cryptocurrencies. It can be seen that bitcoin is the main cryptocurrency and is expected to increase by more than $50 \%$ in a year.

Most Accurate Short and Long Term Price Predictions for July 18, 2020

\begin{tabular}{|c|c|c|c|c|c|c|}
\hline & Price Predictions & Volatility index & Price & Prediction, 24 hours & Prediction, month & Prediction, year \\
\hline 1 & Bitcoin predictions & 1 & $\$ 9127.54$ & $-1.66 \%$ & $-6.56 \%$ & $57.30 \%$ \\
\hline 2 & Ethereum predictions & 7 & $\$ 232.82$ & $-3.50 \%$ & $7.86 \%$ & $74.59 \%$ \\
\hline 3 & Tether predictions & 1 & $\$ 0.999078$ & $-0.09 \%$ & $-0.09 \%$ & $39.39 \%$ \\
\hline 4 & XRP predictions & 43 & $\$ 0.194428$ & $-2.17 \%$ & $-5.53 \%$ & $-0.82 \%$ \\
\hline 5 & Bitcoin Cash predictions & 10 & $\$ 222.95$ & $-6.71 \%$ & $-11.16 \%$ & $27.00 \%$ \\
\hline 6 & Bitcoin SV predictions & 55 & $\$ 171.75$ & $-6.36 \%$ & $-18.45 \%$ & $92.90 \%$ \\
\hline 7 & Cardano predictions & 83 & $\$ 0.119991$ & $1.40 \%$ & $54.79 \%$ & $132.25 \%$ \\
\hline 8 & Chainlink predictions & 89 & $\$ 7.86$ & $21.88 \%$ & $50.51 \%$ & $131.90 \%$ \\
\hline 9 & Litecoin predictions & 5 & $\$ 41.86$ & $-5.71 \%$ & $-7.98 \%$ & $-4.69 \%$ \\
\hline 10 & Binance Coin predictions & 42 & $\$ 17.03$ & $-1.35 \%$ & $2.29 \%$ & $30.99 \%$ \\
\hline
\end{tabular}

Table 10 Table 5.1 shows the effect of activities of the US dollar. Notice the deep fall in 2008. It is highly possible the deep fall was due to the financial crisis in 2008. Despite the coronavirus in 2020, it is expected that it would have little to no effect on the dollar at the end of 2020 even though there have been increased transactions in cryptocurrency during lockdown.

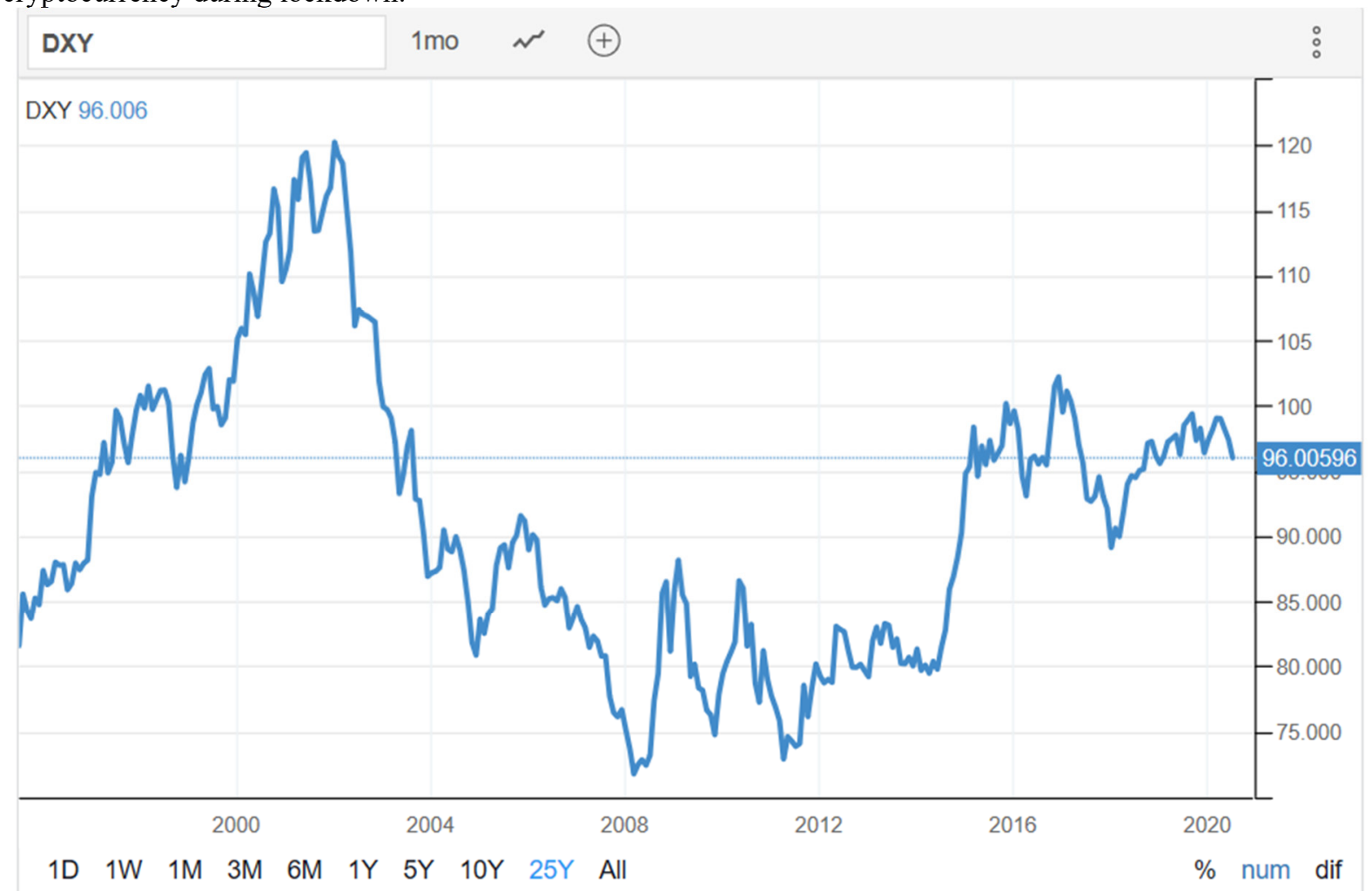

\section{Result}

Since the Asymp Sig. the level of this test is 0.071 which is far much higher than the 0.05 acceptance region, we fail to reject the null hypothesis and conclude that the effect of the crypto currency on the value of the dollar is 
significantly low. Also, it can be deduced from Table 9 that prices of bitcoin are expected to increase by $57 \%$. This means that demand for bitcoin is expected to rise significantly but the fiat dollar usage has remained fairly stable. Thus, having little to no effect on the use of fiat dollar currency in the future (as seen in table 10).

\section{Discussion}

This study sought to establish a relationship between digital currency and fiat dollar. Technological advancements have made possible a cashless environment, where transactions take place with the use of debit and credit cards and other forms of online payments. Most importantly, this environment is usually thought to be secure and easy to navigate, even when the user is considered a laggard in adopting a new technology. Cryptocurrencies promise to revolutionise payments once more. Made possible by encryption techniques, the Bitcoin offers a transparent policy that is accessible by all the peers of the network. In this sense, verification and authentication of any all transactions can be done without the need for a central regulatory body. However, it is uncertain whether this information can be easily processed by the layperson. Moreover, assuming that the aim is for Bitcoin to eventually be accepted for regular transactions, there is a need for a greater adoption of the currency by both end users and businesses.

Since capital controls were imposed, many individuals turned to the Bitcoin technology for their everyday transactions with businesses and individuals residing abroad, or simply out of fear for an imminent deposit haircut. In doing so, awareness regarding the technology has increased but adoption remains low. While users exhibit a vivid interest, they don't necessarily trust the technology, possibly because they are still not acquainted enough with how transactions take place, how these get verified and validated and so on and so forth. Along these lines, we posit that the focus should not be aimed at if and how the Bitcoin protocol can be used for illicit activities, such as money laundering and the likes, but rather increasing awareness on the underlying technologies that make Bitcoin, and other altcoins, possible. These would include the blockchain, i.e., the distributed ledger technology that is used for maintain any and all records of all transactions across the network, and smart contracts, i.e., selfexecutable software that is embedded in the blockchain and can facilitate the development of a number of other innovative applications. This way users will be able to appreciate the security and anonymity provided by the technology, what is meant by irreversibility and how double spending is completely avoidable. Most importantly, we consider that users, i.e., consumers but most importantly businesses, will be able to grasp the numerous opportunities for developing new business scenarios building on the Bitcoin technology and the blockchain, increase their level of innovativeness, and propose new entrepreneurial models. In other words, attention should be paid in how technologies like the Bitcoin can enable decentralized trusted peer-to peer transaction ledger systems and applications, such as the blockchain (Giaglis and Kypriotaki, 2014) and help develop sustainable business models (Wörner et al., 2016). This will support developmental efforts, which are particularly needed to overcome the still present financial crisis. As Worner et al. (2016) show, many firms already leverage this new type of money to innovate, and in doing so, they create new markets and even remove intermediaries, such as central authorities from the picture.

\section{Recommendation and Future Research}

It is worth considering that despite Bitcoin's current market valuation, there are many obstacles for its full use as an alternative payment mechanism. The government should do its best to support the use of bitcoin as it is the future. Adequate laws, regulation and some sort of control should be implemented with cryptocurrencies to limit fraud activities and irregularities. However, for the economy to fully thrive, it is important that fiat currency should still dominate the financial market. The technology itself and the industry structured around it need to overcome the obstacles of digital currencies so that both the Bitcoin, or other cryptocurrencies, and the underlying technologies, i.e., distributed ledger technology and smart contracts, can meet their full commercialisation. It would thus be interesting to investigate further along this dimension and to examine whether and how these obstacles can be lifted. Another direction for future research would be to delve deeper into consumers' trust and risk perceptions and investigate whether these are similar or inherently different from the perceptions they hold towards fiat currencies. Since this study is highly predictive, it is mostly based on the author's perception and evidence available, further research to this still needs to be undertaken.

\section{Conclusion}

Bitcoin has already succeeded. It was created for a reason, which was to help mitigate the financial crisis, and it has worked significantly. Even if the demand declines or the price decreases, it has done its job. Cryptocurrency remains the future. There is no denying that. It will become more popular than it already is. But despite its growth, this may not have an inverse effect on the use of the fiat dollar currency. It is very important for both to thrive as it gives the user the option to choose and helps in the development of the economy. The federal government more than ever needs to be very cautious in whatever decision it takes as there is a rumor going on that the government in the US is creating its own cryptocurrency, Fedcoin. Whatever action the Government takes must be of the 
benefit of the economy and its users.

\section{Future Research}

There are over 1600 cryptocurrencies in the world today, and as complex as this is, it is expected to become even more complex as more cryptocurrencies are created. There is therefore a need to embark on further research in this area. For starters, due to the high volatility in cryptocurrencies, this will most likely deter institutions from fully accepting it for the long haul. A possible research exists in this area to find how it might affect the prospective existence of cryptocurrencies, institutions and the financial system as a whole. Another direction could be to explore the negative effects of "halving" cryptocurrencies which is designed to be an anti-inflationary measure, i.e ensure scarcity of bitcoin. An equilibrium achieved by finding a balance between its supply and demand might just prove to be what cryptocurrencies need to be more popular to users as a medium of exchange. If explored further, it might even help reduce the very volatility that has made cryptocurrencies less favorable to fiat currencies.

\section{References}

Assink, M. (2006). Inhibitors of disruptive innovation capability: a conceptual model. European Journal of Innovation Management, 9(2), 215-233.

Beck, R., \& Müller-Bloch, C. (2017). Blockchain as Radical Innovation: A Framework for Engaging with Distributed Ledgers as Incumbent Organization. In 50th Hawaii International Conference on System Sciences.

Burgoyne, M. (2013, October 23). Canadian Bitcoin Law: All You Need to Know. Retrieved June 30, 2017, from http://www.coindesk.com/federal-bitcoin-law-canada/

Burks, C. (2017). Bitcoin: Breaking Bad or Breaking Barriers? North Carolina Journal of Law \& Technology, 18, 244-282.

Chaum, D. (1983). Blind Signatures for Untraceable Payments. In D.

Chaum, R. L. Rivest, \& A. T. Sherman (Eds.), Advances in Cryptology (pp. 199-203). Boston, MA: Springer US. Retrieved from http://link.springer.com/10.1007/978-1-4757-0602-4_18

Darlington, J. K. I. (2014). The Future of Bitcoin: Mapping the Global Adoption of World's Largest Cryptocurrency Through Benefit Analysis (Honors Thesis Projects). University of Tennessee. Retrieved from http://trace.tennessee.edu/utk chanhonoproj/1770

Dierksmeier, C., \& Seele, P. (2016). Cryptocurrencies and Business Ethics. Journal of Business Ethics, 1-14.

Dwyer, G. P. (2015). The economics of Bitcoin and similar private digital currencies. Journal of Financial Stability, $17,81-91$

European Central Bank. (2012). Virtual Currency Schemes. ECB. Retrieved from https://www.ecb.europa.eu/pub/pdf/other/virtualcurrencyschemes201210en.pdf

Fortune. (2016, September 20). Bitcoin Is Real Money, Judge Rules in J.P. Morgan Hack. Retrieved February 2, 2017, from http://fortune.com/2016/09/20/judge-rules-bitcoin-is-money/

Gans, J. S., \& Halaburda, H. (2015). Some Economics of Private Digital Currency. In A. Goldfarb, S. M. Greenstein, \& C. E. Tucker (Eds.), Economic Analysis of the Digital Economy (pp. 257-276). University of Chicago Press. Retrieved from http://www.bibliovault.org/BV.landing.epl?ISBN=9780226206981

Giaglis, G. M., \& Kypriotaki, K. N. (2014). Towards an Agenda for Information Systems Research on Digital Currencies and Bitcoin. In W. Abramowicz \& A. Kokkinaki (Eds.), Business Information Systems Workshops (Vol. 183, pp. 3-13). Springer International Publishing.

IMF. (2016). Virtual Currencies and Beyond: Initial Considerations (IMF Staff Discussion Note No. SDN/16/03). International Monetary Fund. Retrieved from http://www.imf.org/external/pubs/ft/sdn/2016/sdn1603.pdf

Karas, T. (2015, September 21). Bitcoin entrepreneurs see their opportunity in the damaged economies of Greece and Argentina. Retrieved June 30, 2017, from http://mashable.com/2015/09/21/greecebitcoin-atms/

Kharpal, A. (2017, December 4). Bitcoin value rises over $\$ 1$ billion as Japan, Russia move to legitimize cryptocurrency. Retrieved June 30, 2017, from http:/www.cnbc.com/2017/04/12/bitcoinprice-rises-japanrussia-regulation.html

Lo, S., \& Wang, C. J. (2014). Bitcoin as Money? (Current Policy Perspectives No. 14-4). Federal Reserve Bank of Boston.

Meiklejohn, S., Pomarole, M., Jordan, G., Levchenko, K., McCoy, D., Voelker, G. M., \& Savage, S. (2016). $A$ fistful of Bitcoins: characterizing payments among men with no names. Communications of the ACM, 59(4), 86-93.

Miers, I., Garman, C., Green, M., \& Rubin, A. D. (2013). Zerocoin: Anonymous Distributed E-Cash from Bitcoin (pp. 397-411). IEEE. Retrieved from http://ieeexplore.ieee.org/document/6547123/

Miller, A., Kosba, A., Katz, J., \& Shi, E. (2015). Nonoutsourceable Scratch-Off Puzzles to Discourage Bitcoin Mining Coalitions. In 22nd ACM SIGSAC Conference on Computer and Communications Security (pp. 680691). ACM Press. Mount, I. (2015, October 7). 